\title{
An Unusual Case of Severe Haemorrhage and Small Bowel Injury Following Percutaneous Suprapubic Catheter Insertion
}

\author{
Jes Verwey ${ }^{\mathrm{a}}$, Martha Nixon ${ }^{\mathrm{a}}$, Jacob A Akoha,
}

\begin{abstract}
Suprapubic catheterisation is a useful alternative to urethral catheterisation but it carries potentially serious complications, including bowel injury and infection. We present a case of severe intraabdominal haemorrhage following a suprapubic catheter insertion using the Seldginger technique. The patient's risk of complications was increased by a previous hysterectomy. This case demonstrates the use of ultrasound guidance during suprapubic catheterisation in high risk patients, such as those with previous abdominal or pelvic surgery.
\end{abstract}

Keywords: Bowel perforation; Haemorrhage; Suprapubic cystostomy; Seldinger technique

\section{Introduction}

Insertion of suprapubic catheter (SPC) is a common urological procedure. It is indicated for treatment of acute urinary retention not amenable to urethral catheterisation and in the long-term treatment of patients with bladder outflow

Manuscript accepted for publication January 19, 2012

${ }^{\mathrm{a}}$ Gastroenterology, Surgery \& Renal Services Directorate, Plymouth Hospitals NHS Trust, Derriford Hospital, Plymouth PL6 8DH,United Kingdom

${ }^{\mathrm{b} C}$ Corresponding author: Jacob A Akoh, Consultant General Surgeon, Level 04, Derriford Hospital, Plymouth PL6 8DH, United Kingdom. Email: Jacob.akoh@nhs.net

doi:10.4021/wjnu3w obstruction and neuropathic bladders [1]. Compared with urethral catheterisation, SPC is associated with a superior quality of life, reduced infection rates and less pain and discomfort. It also enables patients, especially males to attempt normal voiding [2-5]. There is evidence to suggest that SPC are more acceptable to patients $[3,4,6]$, with one study suggesting that $89 \%$ prefer SPC to urethral catheters [1]. We present a case of elective percutaneous insertion of a SPC which resulted in significant intra-abdominal haemorrhage and bowel injury, requiring emergency laparotomy, intensive care admission, prolonged hospitalisation and extensive rehabilitation. Although cases of bowel injury have been presented previously, there are few documented cases of significant intra-abdominal haemorrhage.

\section{Case Report}

EP, an 82 year female, presented to the medical assessment unit with collapse 11 hours following a percutaneous SPC insertion for incontinence at a nearby hospital. The procedure had been performed by a consultant urologist who used a flexible cystoscope to fill the bladder prior to locating the bladder with the Seldinger needle. Some difficulty was encountered when passing the Seldinger needle into the bladder. Once the needle was in place, it was a straight forward SPC insertion using a mediplus Seldinger kit. EP felt well following the procedure and was discharged later that day.

On the journey home she began feeling unwell and collapsed whilst getting out of the car, and again after entering her home. She had no cardiac symptoms or history of a fall. Her past medical history included atrial fibrillation (on warfarin and bisoprolol), hypertension, bilateral hip replacement, hysterectomy and open cholecystectomy. During the initial clerking she had two episodes of dizziness followed by unresponsiveness lasting 30 seconds. On examination her observations were within normal limits (pulse rate 84 per minute, blood pressure $162 / 94 \mathrm{mmHg}$ ). Respiratory examination revealed some crackles in the left lung base. The abdomen was distended with lower abdominal tenderness and percussion tenderness. Neurological and cardiological examinations were normal. Investigations revealed a raised 


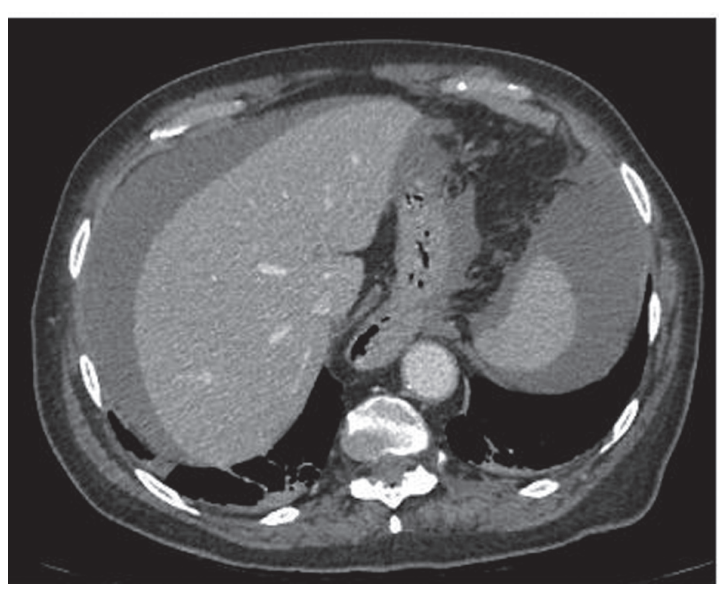

Figures 1. CT abdomen showing blood surrounding liver and spleen.

white cell count of $14.9 \times 10^{9} / \mathrm{L}$ (normal range $3.5-9.2 \times$ $10^{9} / \mathrm{L}$ ), haemoglobin of $11.4 \mathrm{~g} / \mathrm{dL}$ (normal range $12-15.5 \mathrm{~g} /$ $\mathrm{dL}$, reduced from $14.1 \mathrm{~g} / \mathrm{dL}$ four months previously) and an INR (international normalised ratio) of 3.1. Chest and abdominal x-rays were normal.

On examination by the general surgical team, she was afebrile with a blood pressure of 180/92 $\mathrm{mmHg}$ and a pulse rate of 70 per minute. There was demonstrable abdominal tenderness particularly in the epigastric area but without guarding. The SPC was draining clear urine but there was a small amount of blood leaking from around the insertion site. An abdominal CT scan was requested. Whilst waiting for the CT scan, she had two hypotensive episodes that responded to fluid resuscitation. The CT scan showed the SPC to be in situ and presence of high-density fluid within the abdomen and pelvis in keeping with haemorrhage (Fig. 1).

EP was given Beriplex ${ }^{\circledR}$ (prothrombin complex concentrate) to reverse her INR. At emergency laparotomy, an injury to the small bowel was identified with a large haematoma in the mesentery and approximately $2400 \mathrm{~mL}$ of blood with clots in the peritoneal cavity. A small bowel resection with end to end anastomosis was performed. Post operatively she required intensive care for ongoing cardiovascular support in the form of close fluid balance and inotropic support in the intensive therapy unit. Her post operative recovery was complicated by confusion, generalised weakness and sepsis of unknown source. She gradually improved in all areas and 26 days later was discharged to a community hospital for 15 days of further rehabilitation.

\section{Discussion}

Insertion of SPC is associated with complications in around $10 \%$ and mortality in $0.8-1.8 \%$ of cases $[1,7]$. The commonest complication is urinary tract infection [1] but bowel

Table 1. Modified Guidelines From the British Association of Urological Surgeons "Guidelines for Safe SPC Insertion" [20]

Consider if a SPC is superior to a urethral catheter in each individual patient.

Patients need to be consented and provided with written and verbal information.

If there is no one skilled to do SPC, then a suprapubic aspiration with 21 Gauge needle can be used to temporarily alleviate symptoms.

If the bladder is not filled with at least $300 \mathrm{mls}$ or in spinal cord injury, the patient should have regional or general anaesthetic

If the urine is likely to be colonised with bacteria, patients should have prophylactic antibiotics.

Closed techniques should only be performed by trained professionals who understand the risks.

US should be used to aid SPC insertion and by individuals who are trained and experienced.

If there is no previous lower abdominal or pelvic surgery, a closed technique can be used. If the bladder is palpable and that urine can be easily aspirated from the catheter track.

If history of lower abdominal surgery or a non-palpable bladder, or obese then an open technique or with imaging should be used to exclude bowel loops. 
injury [8-14] occurs in $2.4-2.7 \%$ [1, 7]. The risk of complications in patients with previous abdominal or pelvic surgery is increased from $5 \%$ to $31 \%$ [1]. In such patients, ultrasound scan (US) can be used to exclude interposed bowel loops thereby reducing the risk of bowel injury [15-17]. We believe this is the first reported case of severe abdominal haemorrhage complicating SPC insertion.

The Seldinger technique for SPC insertion has been shown to be a popular technique among urologists as it is thought to be a safer approach compared to the traditional trochar method [18, 19]. However, the evidence for this opinion is not supported by any randomised controlled trial. The British Journal of Urology International [20] guidance on the Seldinger technique states that lower abdominal scars are a relative contraindication to the procedure and that the bladder needs to be filled to at least $200-300 \mathrm{mls}$ [19]. However, a case of delayed small bowel perforation following insertion of a SPC by the Seldinger technique [21] questions the safety of the technique. It is debatable whether distending the bladder with $200-300 \mathrm{mls}$ is sufficient to push away the structures lying in close proximity to the bladder.

This case highlights a serious and potentially life-threatening complication of SPC insertion resulting in major surgery, intensive care admission and a lengthy hospital stay. We suspect the suprapubic trochar went through the small bowel mesentery before entering the bladder. EP had a previous hysterectomy that might have increased her risk of complications [1]. EP also presented to a different specialty in our hospital with ambiguous and conflicting symptoms and signs. All of these probably contributed to the delay in her diagnosis and treatment. Although SPC is a simple procedure, all healthcare professionals need to be aware of, and have a high index of suspicion for the potential complications, in order to ensure adequate and efficient management. To ensure safe practice, we advocate that the British Association of Urological Surgeons' recommendations for SPC insertion (Table 1) [20] should be adopted by all undertaking the procedure.

This case demonstrates that the risk of complications is increased in patients with previous abdominal or pelvic surgery. It offers strong support for the use of ultrasound guidance in inserting SPC in patients at risk.

\section{References}

1. Ahluwalia RS, Johal N, Kouriefs C, Kooiman G, Montgomery BS, Plail RO. The surgical risk of suprapubic catheter insertion and long-term sequelae. Ann R Coll Surg Engl. 2006;88(2):210-213.

2. Sethia KK, Selkon JB, Berry AR, Turner CM, Kettlewell MG, Gough MH. Prospective randomized controlled trial of urethral versus suprapubic catheterization. Br J Surg. 1987;74(7):624-625.
3. Branagan GW, Moran BJ. Published evidence favors the use of suprapubic catheters in pelvic colorectal surgery. Dis Colon Rectum. 2002;45(8):1104-1108.

4. McPhail MJ, Abu-Hilal M, Johnson CD. A meta-analysis comparing suprapubic and transurethral catheterization for bladder drainage after abdominal surgery. $\mathrm{Br} \mathrm{J}$ Surg. 2006;93(9):1038-1044.

5. Andersen JT, Heisterberg L, Hebjorn S, Petersen K, Stampe Sorensen S, Fischer-Rasmussen W, Molsted Pedersen L, et al. Suprapubic versus transurethral bladder drainage after colposuspension/vaginal repair. Acta Obstet Gynecol Scand. 1985;64(2):139-143.

6. Krane LS, Bhandari M, Peabody JO, Menon M. Impact of percutaneous suprapubic tube drainage on patient discomfort after radical prostatectomy. Eur Urol. 2009;56(2):325-330.

7. Sheriff MK, Foley S, McFarlane J, Nauth-Misir R, Craggs M, Shah PJ. Long-term suprapubic catheterisation: clinical outcome and satisfaction survey. Spinal Cord. 1998;36(3):171-176.

8. Noller KL, Pratt JH, Symmonds RE. Bowel perforation with suprapubic cystostomy Report of two cases. Obstet Gynecol. 1976;48(1 Suppl):67S-69S.

9. Liau SS, Shabeer UA. Laparoscopic management of cecal injury from a misplaced percutaneous suprapubic cystostomy. Surg Laparosc Endosc Percutan Tech. 2005;15(6):378-379.

10. Wu CC, Su CT, Lin AC. Terminal ileum perforation from a misplaced percutaneous suprapubic cystostomy. Eur J Emerg Med. 2007;14(2):92-93.

11. Barai KP, Islam S. Suprapubic catheterization complicated by an iatrogenic enterocutaneous fistula: a case report. Cases J. 2009;2:9311.

12. Mongiu AK, Helfand BT, Kielb SJ. Small bowel perforation during suprapubic tube exchange. Can J Urol. 2009;16(1):4519-4521.

13. Witham MD, Martindale AD. Occult transfixation of the sigmoid colon by suprapubic catheter. Age Ageing. 2002;31(5):407-408.

14. Parikh A, Chapple CR, Hampson SJ. Suprapubic catheterisation and bowel injury. Br J Urol. 1992;70(2):212213.

15. Ahmed SJ, Mehta A, Rimington P. Delayed bowel perforation following suprapubic catheter insertion. BMC Urol. 2004;4(1):16.

16. Aguilera PA, Choi T, Durham BA. Ultrasound-guided suprapubic cystostomy catheter placement in the emergency department. J Emerg Med. 2004;26(3):319-321.

17. Lawrentschuk N, Lee D, Marriott P, Russell JM. Suprapubic stab cystostomy: a safer technique. Urology. 2003;62(5):932-934.

18. Gulur DM, Housami F, Drake MJ. Suprapubic catheter insertion using the Seldinger technique, with the Mediplus SPC kit. British Journal of Urology Inter- 
national, website atlas of surgery and surgical devices.2008. http://www.bjui.org/ContentFullitem. aspx? SectionType $=1 \& i d=173$. Accessed 20 November 2011.

19. Vasdev N, Kachroo N, Mathur S, Pickard S. Suprapubic bladder catheterisation using the Seldinger technique. Internet Journal Urology. 2007;5(1).
20. Harrison SC, Lawrence WT, Morley R, Pearce I, Taylor J. British Association of Urological Surgeons' suprapubic catheter practice guidelines. BJU Int. 2011;107(1):7785.

21. Jackson BL, Leeder PC, Williams JH. Delayed Presentation of Small Bowel Injury During Suprapubic Catheterisation. JSCR. 2010;2:2. 